\title{
Association between mobilization of circulating endothelial progenitor cells and time or degree of injury from angioplasty in patients with exertional angina: A prospective study
}

\author{
MINGDONG GAO*, QINGHAI YAO*, YIN LIU, FUQIANG SUN, YUDONG MA and GENYI SUN \\ Department of Cardiology, Tianjin Chest Hospital, Heping, Tianjin 300051, P.R. China
}

Received September 16, 2014; Accepted May 8, 2015

DOI: $10.3892 /$ etm.2015.2571

\begin{abstract}
The aim of the present study was to investigate the effect of coronary artery angioplasty on the recruitment of circulating endothelial progenitor cells (EPCs) in patients with angina pectoris. A total of 66 patients treated by coronary stenting were enrolled in the PCI group and 17 patients that underwent angiography alone were enrolled in the control group. The EPC count in the blood was measured by flow cytometry prior to and at 1, 3, 5, 7 and $24 \mathrm{~h}$ following angioplasty in the percutaneous coronary intervention (PCI) group, and at three time-points following angiography in the control group. Differences between the two groups included the characteristics of the coronary artery lesions, the incidence of diabetes and family history of coronary heart disease. The mean surface area of the stent deployed was $335.59 \pm 234.99 \mathrm{~mm}^{2}$. No significant change in EPC count was measured in the control group. In the PCI group, a moderate and delayed increase in the number of cluster of differentiation (CD) $34^{+} /$kinase domain receptor $(\mathrm{KDR})^{+}$EPCs occurred at $24 \mathrm{~h}$ post-balloon inflation compared with the baseline level. The $\mathrm{CD} 133-/ \mathrm{CD} 34^{+} / \mathrm{KDR}^{+}$subpopulations showed undulating changes at 3,7 and 24 h post-PCI $(\mathrm{P}=0.016, \mathrm{P}=0.01$ and $\mathrm{P}=0.032$, respectively). An arch shape was displayed in $\mathrm{CD}_{133}{ }^{+} / \mathrm{KDR}^{+}$cells; initially, a reduction occurred at $3 \mathrm{~h}$ and was maintained constantly until $7 \mathrm{~h}(\mathrm{P}=0.003, \mathrm{P}=0.013$ and $\mathrm{P}=0.033$ at 3,5 and $7 \mathrm{~h}$, respectively), after which a slight increase to the baseline level occurred at $24 \mathrm{~h}(\mathrm{P}=0.084)$. The $\mathrm{CD} 133^{+} / \mathrm{CD} 34^{+}$cells increased in stepwise manner until 24 h. The $\mathrm{CD}^{2} 4^{+} / \mathrm{KDR}^{+} \mathrm{EPC}$ change magnitude correlated significantly with a global damage index by partial correlation analysis $(\mathrm{P}<0.001)$. The results suggested that a time-dependent mobilization of EPCs may be initiated by PCI; the change
\end{abstract}

Correspondence to: Dr Yin Liu, Department of Cardiology, Tianjin Chest Hospital, 93 Xi An Road, Heping, Tianjin 300051, P.R. China E-mail: yinliucn@163.com

*Contributed equally

Key words: circulating endothelial progenitor cell, percutaneous transluminal coronary artery angioplasty, mobilization, homing magnitude of the $\mathrm{CD} 34^{+} / \mathrm{KDR}^{+}$cells was associated particularly with endothelial injury degree from the PCI procedure.

\section{Introduction}

Endothelial progenitor cells (EPCs) play an important role in endogenous vascular reparation, and modulate the clinical course of coronary artery disease (1). EPCs have been shown to mobilize from the bone marrow into the circulation and home to sites of vascular injury. They are then incorporated into foci of neovascularization, thereby improving tissue recovery and blood flow in the setting of tissue ischemia and endothelial damage $(2,3)$. Endothelial denudation and endovascular laceration due to rigid stent struts and high-pressure balloon inflations initiate an intensive local inflammatory response and disturb local vascular function. Vascular injury may also produce abnormal neointimal hyperplasia resulting in clinical or sub-clinical in-stent restenosis as well as acute stent thrombosis, a potentially catastrophic complication of coronary stenting. It has been suggested that variations in EPCs in response to vascular injury caused by stenting may affect short-term (acute stent thrombosis) and long-term (restenosis) outcomes of percutaneous coronary intervention (PCI) (4-7). EPC counts following coronary stenting may potentially serve as a predictor for the risk stratification of therapeutic coronary interventions.

EPCs can be identified by the expression of surface markers, such as cluster of differentiation (CD)34 and kinase domain receptor (KDR), the latter of which is the extracellular domain of vascular endothelial growth factor receptor-2 (VEGFR-2). CD133 is highly expressed on immature EPCs, but is lost when they differentiate into mature endothelial cells (8). Immature EPCs can therefore be distinguished by the expression of CD133.

Thomas et al (9) and Lee et al (10) have observed transient changes of $\mathrm{CD}^{2} 4^{+} / \mathrm{KDR}^{+}$EPCs in patients $4-6 \mathrm{~h}$ post-PCI, in non-diabetic and diabetic populations. Previous studies have reported heterogeneous changes of EPC counts following PCI procedures (11-13). However, these studies have not addressed the pattern of recruitment or mobilization of mature and immature EPCs following PCI. The sequential quantitation and characterization of EPCs following coronary stenting may provide new evidence to explain the endothelial recovery and the impact on patient prognosis. 
The present study aimed to measure the sequential changes of mature and immature EPCs in the peripheral blood of patients with exertional angina pectoris prior and subsequent to a PCI procedure. Furthermore, the associations between the extent of EPC motivation and a variety of clinical factors were studied, particularly the association with the degree of endothelial injury during PCI as represented by stent area plus inflating pressure. To exclude confounding factors, such as the homing of EPCs secondary to necrotic myocardium or the presence of other inflammatory substances, strict inclusion criteria for the study population were applied.

\section{Materials and methods}

Study population. Patients who underwent elective and successful PCI treatment between October 2011 and September 2012 were screened for the present study. The inclusion criteria were: i) Presence of typical effort angina; ii) feasibility of complete revascularization of clinically significant stenoses by PCI; and iii) age $\leq 70$ years. Exclusion criteria included: i) Age >70 years; ii) familial hyperlipidemia; iii) the presence of acute or chronic inflammatory disease, ischemic cerebral and peripheral arterial diseases, recent surgery or trauma; iv) acute coronary syndrome (including unstable angina and acute myocardial infarction); v) abnormal hepatic function at least 1 month prior to PCI; vi) patients whose coronary angiography showed coronary artery flow less than thrombolysis in myocardial infarction (TIMI) grade 3, dissection or thrombosis; vii) patients with PCI-associated acute myocardial infarction, acute stent thrombosis, left ventricular ejection fraction (LVEF) $\leq 50 \%$; and viii) prior PCI or coronary artery bypass graft surgery.

Patients who met the inclusion criteria and only underwent angiography were enrolled as controls. Informed consent was obtained from all patients. The study was approved by the Committee for Human Research in Tianjin Chest Hospital (Heping, China).

Percutaneous coronary angioplasty and adjunctive drugs. According to the study protocol, all patients without contraindications were pre-treated with $300 \mathrm{mg}$ aspirin and $300 \mathrm{mg}$ clopidogrel for the first day prior to PCI. Following PCI, the anti-platelet regime was $300 \mathrm{mg}$ aspirin daily for $1 \mathrm{month}$, then $100 \mathrm{mg}$ daily indefinitely, and $75 \mathrm{mg}$ clopidogrel daily for 12 months. Other medications such as $\beta$-blockers, statins and angiotensin-converting enzyme inhibitors (ACEIs) were continued as required. All patients received a standard dose of unfractionated heparin $(100 \mathrm{U} / \mathrm{kg})$ prior to the angioplasty procedure.

Blood samples and cardiac progenitor cell flow cytometry. Peripheral blood samples $(2 \mathrm{ml})$ were collected following diagnostic angiography (baseline level) and immediately subsequent to the end of the PCI process (this was defined as the $1 \mathrm{~h}$ time-point, despite the actual time being $<1 \mathrm{~h}$ from the first balloon dilatation). Subsequently, blood samples were obtained for time-points 3, 5, 7 and $24 \mathrm{~h}$ from the first balloon dilation. Blood samples of angiography patients were collected pre-procedure and 7 and $24 \mathrm{~h}$ post-procedure in the control group. The blood samples for stem cell assessment were stored at room temperature and analyzed within $20 \mathrm{~min}$. To $100 \mu \mathrm{l}$ peripheral blood was added $10 \mu \mathrm{l}$ fluorescent anti-human $\mathrm{CD} 4^{+}$antibody (BD Biosciences, San Jose, CA, USA), $10 \mu 1$ anti-human KDR-PE (BD Biosciences), $5 \mu \mathrm{l}$ APC-conjugated anti-CD133 (Miltenyi Biotec GmbH, Bergisch Gladbach, Germany) or fluorescent isotype-identical antibody controls. After undiluted samples were stained with antibodies for $30 \mathrm{~min}$ in the dark, erythrocytes were lysed using a lysing solution (BD Biosciences), and samples were centrifuged at $200 \mathrm{x}$ g for $10 \mathrm{~min}$. The mononuclear cell population, which includes EPCs, was isolated from the whole blood forward and side scatter profile in a FACSCalibur flow cytometer (BD Biosciences), then analyzed with Cell Quest ${ }^{\mathrm{TM}}$ software (BD Biosciences). The method of EPC quantification was consistent with published standard practices and recommendations $(14,15)$. Classic EPCs are described as $\mathrm{CD}^{+}{ }^{+} / \mathrm{KDR}^{+}$, the mature EPC subpopulation was considered as $\mathrm{CD} 133 \% \mathrm{CD} 34^{+} / \mathrm{KDR}^{+}$and immature or naive EPCs as $\mathrm{CD} 33^{+} / \mathrm{CD} 34^{+} / \mathrm{KDR}^{+}$. Immature $\mathrm{CD} 34^{+}$and $\mathrm{KDR}^{+}$cells were marked as $\mathrm{CD}_{133}{ }^{+} / \mathrm{CD} 34^{+}$and $\mathrm{CD} 133^{+} / \mathrm{KDR}^{+}$. Counts of the different types of EPC were reported as cells per 200,000 total events. The measurements were performed by one operator who was blinded to the status of the patients. To assess the reproducibility of the results, circulating EPCs were measured twice in the first 5 consecutive patients from two blood samples drawn 1 day prior to PCI.

The stent was assumed to be cylindrical following its deployment from the stent-balloon. The surface area of the stent (perimeter $x$ length) in contact with the vascular endothelium and the maximum stent inflation pressure were taken to be representative of the severity of endothelial damage.

Quantitative parameters of coronary angiography and angioplasty. Analysis of coronary angiograms was performed prior to (baseline level) and subsequent to PCI by two independent cardiologists from Tianjin Chest Hospital. Vessels with diameters $>2.25 \mathrm{~mm}$ were treated. Procedural success of the PCI was defined as a decrease in diameter stenosis $\geq 50 \%$ and/or a residual narrowing of $<30 \%$ diameter stenosis.

Quantitative parameters for endothelial injury. Mechanical trauma induced by high-pressure inflation and rigid stent struts inevitably results in endothelial denudation and endovascular laceration. In the present study, the stent surface area was used to quantify the amount of endothelium damaged by the stenting procedure. The stent-inflation pressure was also used to estimate the extent of the endothelial trauma caused by the PCI procedure. In order to evaluate the vascular damage during PCI, the product of the stent surface area and the stent-inflation pressure was determined and regarded as a global injury integral. The present study focused predominantly on the correlation between the extent of endothelial injury and the alterations of $\mathrm{CD}_{3} 4^{+} / \mathrm{KDR}^{+}$and $\mathrm{CD} 133 \% \mathrm{CD} 34^{+} / \mathrm{KDR}^{+} \mathrm{EPCs}$ measured at baseline and $24 \mathrm{~h}$ post-PCI.

Statistical analysis. Data are presented as mean \pm standard deviation for continuous variables or frequency percentages for categorical variables. Kolmogorov-Smirnov testing was applied to assess normality of distribution for continuous variables. Student's paired t-tests were performed to compare the 
Table I. Comparison of clinical characteristics between the two groups.

\begin{tabular}{|c|c|c|c|}
\hline Clinical parameter & PCI group, $n=66$ & Control group, $\mathrm{n}=17$ & P-value \\
\hline \multicolumn{4}{|l|}{ Basic clinical characteristics } \\
\hline Age, years & $59.54 \pm 9.06$ & $57.32 \pm 6.30$ & NS \\
\hline Male $(\%)$ & $49(74.2)$ & $11(68.7)$ & NS \\
\hline $\mathrm{BMI}, \mathrm{kg} / \mathrm{m}^{2}$ & $24.6 \pm 3.4$ & $23.9 \pm 2.8$ & NS \\
\hline Hypertension (\%) & $35(53)$ & $7(43.8)$ & NS \\
\hline ACEI or ARB treatment $(\%)$ & $29(43.9)$ & $7(43.8)$ & NS \\
\hline Diabetes (\%) & $24(36.4)$ & $2(11.8)$ & $<0.05$ \\
\hline Current smoker (\%) & $20(30.3)$ & $4(23.5)$ & NS \\
\hline Family history of coronary disease $(\%)$ & $5(31.3)$ & $2(5.9)$ & $<0.05$ \\
\hline Single-vessel disease $(\%)$ & $36(54.5)$ & $5(31.2)$ & $<0.05$ \\
\hline Two-vessel disease (\%) & $16(24.2)$ & $2(12.5)$ & $<0.05$ \\
\hline Three-vessel disease (\%) & $14(18.75)$ & $1(6.25)$ & $<0.05$ \\
\hline Statin therapy prior to PCI (\%) & $66(100)$ & $17(100)$ & NS \\
\hline \multicolumn{4}{|l|}{ Laboratory characteristics } \\
\hline Plasma low density cholesterol, mmol/1 & $2.54 \pm 0.81$ & $2.21 \pm 0.32$ & NS \\
\hline Hs-CRP, mg/l & $1.55 \pm 2.83$ & $0.62 \pm 0.78$ & NS \\
\hline White cell count $\left(\mathrm{x} 10^{9} / \mathrm{l}\right)$ & $6.63 \pm 1.35$ & $6.39 \pm 1.23$ & NS \\
\hline Lymphocyte count $\left(\times 10^{9} / 1\right)$ & $1.62 \pm 0.44$ & $1.64 \pm 0.31$ & NS \\
\hline Monocyte count $\left(\mathrm{x} 10^{9} / \mathrm{l}\right)$ & $0.50 \pm 0.4$ & $0.51 \pm 0.32$ & - \\
\hline Maximum value of CKMB pre-PCI, U/l & 22 & 19 & - \\
\hline Minimum value of CKMB post-PCI or CAG, U/l & 19 & 20 & - \\
\hline Maximum value of troponin I pre-PCI, ng/ml & 0.9 & 0.81 & - \\
\hline Minimum value of troponin I post-PCI or CAG, $\mathrm{ng} / \mathrm{ml}$ & 0.9 & 0.21 & - \\
\hline \multicolumn{4}{|l|}{ Procedural details } \\
\hline Drug-eluting stent $(\%)$ & $66(100)$ & - & \\
\hline Stent surface per subject, $2 \pi \mathrm{R} x$ length, $\mathrm{mm}^{2}$ & $335.59 \pm 234.99$ & - & \\
\hline
\end{tabular}

Unless otherwise indicated, data are expressed as mean \pm standard deviation or rate. Significant differences between the two groups are found for diabetes history, family history of coronary disease and the extent of the coronary artery lesion. BMI, body-mass index; ACEI, angiotensin converting enzyme inhibitor; ARB, angiotensin II receptor blocker; Hs-CRP, high sensitivity C-reactive protein; PCI, percutaneous coronary intervention; $\mathrm{CAG}$, coronary angiography; $\mathrm{CKMB}$, creatine kinase; R, radius; NS, not significant.

serial changes in cell counts with baseline or the lowest value following a percutaneous transluminal coronary angioplasty procedure. $\mathrm{P}<0.05$ was considered to indicate a statistically significant difference. The correlations of changed magnitude of EPCs and trauma parameters (stent surface area/global injury integral) were explored by partial correlation. Analyses and error bars were performed with the SPSS statistical software package (version 18.0; SPSS Inc., Chicago, IL, USA).

\section{Results}

Patient characteristics and progenitor count. The 66 patients fulfilling the inclusion/exclusion criteria were enrolled in the PCI group and samples were taken from them at 6 time-points. Another 17 patients who only underwent angiography were distributed into a control group with samples taken at 3 time-points: Baseline, and 7 and $24 \mathrm{~h}$ post-angiography. A total of 61 patients $(92.4 \%)$ had a single vessel treated and 5 patients $(7.6 \%)$ had 2 vessels treated with a mean stent surface area of $335.59 \pm 234.99 \mathrm{~mm}^{2}$ per patient. Clinical characteristics of the two groups are shown in Table I. There was no significant difference between the two groups with the exception of diabetic incidence, angiographic characteristics and family history of coronary heart disease.

EPC counts are presented as mean \pm standard deviation of cells per 200,000 events and the trends post-PCI are shown in error bar charts (Fig. 1). No significant elevation in the count of $\mathrm{CD}_{3} 4^{+} / \mathrm{KDR}^{+} \mathrm{EPCs}$ was found in the control group compared with the PCI group at baseline, but increased numbers of $\mathrm{CD} 133^{+} / \mathrm{CD} 34^{+} / \mathrm{KDR}^{+}$and $\mathrm{CD} 133^{+} / \mathrm{CD} 34^{+}$cells, which were immature subpopulations of $\mathrm{CD} 34^{+} / \mathrm{KDR}^{+}$or immature $\mathrm{CD} 34^{+}$cells, respectively, were observed. A stable $\mathrm{CD}^{+} 4^{+} / \mathrm{KDR}^{+}$count was shown within $7 \mathrm{~h}$ following the PCI procedure, and a mild and delayed upregulation was shown at $24 \mathrm{~h}$. The levels of the immature $\mathrm{CD} 133^{+} / \mathrm{CD} 34^{+} / \mathrm{KDR}^{+}$cell subpopulation were relatively stable during the procedure. Undulating changes were seen in the $\mathrm{CD} 133^{-} / \mathrm{CD}^{2} 4^{+} / \mathrm{KDR}^{+}$ subpopulation level at the 3,7 and $24 \mathrm{~h}$ time-points $(\mathrm{P}=0.016$, $\mathrm{P}=0.01$ and $\mathrm{P}=0.032$, respectively) and no tendency to return 
Table II. Counts of endothelial progenitor cells and subpopulations in the PCI and control group per 200,000 events.

\begin{tabular}{|c|c|c|c|c|c|}
\hline Time-points & $\mathrm{CD} 34^{+} / \mathrm{KDR}^{+}$ & $\mathrm{CD} 33^{-} / \mathrm{CD} 34^{+} / \mathrm{KDR}^{+}$ & $\mathrm{CD} 133^{+} / \mathrm{CD} 34^{+} / \mathrm{KDR}^{+}$ & $\mathrm{KDR}^{+} / \mathrm{CD} 133^{+}$ & $\mathrm{CD} 34^{+} / \mathrm{CD} 133^{+}$ \\
\hline \multicolumn{6}{|l|}{ PCI group $(n=66)$} \\
\hline Baseline count & $27.28 \pm 13.61$ & $16.23 \pm 16.31$ & $6.94 \pm 9.51^{\mathrm{d}}$ & $14.43 \pm 15.32$ & $8.03 \pm 5.71^{\mathrm{d}}$ \\
\hline $1 \mathrm{~h}$ post-PCI & $26.84 \pm 19.52$ & $18.05 \pm 28.12$ & $7.52 \pm 9.33$ & $13.70 \pm 14.53$ & $10.80 \pm 10.61$ \\
\hline $3 \mathrm{~h}$ post-PCI & $25.28 \pm 19.68$ & $28.72 \pm 50.39^{b}$ & $7.34 \pm 8.56$ & $8.37 \pm 6.88^{a}$ & $12.62 \pm 13.41^{\mathrm{a}}$ \\
\hline $5 \mathrm{~h}$ post-PCI & $27.37 \pm 22.57$ & $20.28 \pm 26.95$ & $8.55 \pm 10.55$ & $9.32 \pm 10.31^{\mathrm{a}}$ & $11.51 \pm 15.76$ \\
\hline $7 \mathrm{~h}$ post-PCI & $27.65 \pm 23.13$ & $15.32 \pm 17.73^{\mathrm{b}}$ & $8.49 \pm 10.32$ & $10.03 \pm 11.96^{\mathrm{a}}$ & $12.60 \pm 15.21$ \\
\hline $24 \mathrm{~h}$ post-PCI & $43.50 \pm 29.59^{\mathrm{a}}$ & $26.38 \pm 22.93^{\mathrm{a}, \mathrm{c}}$ & $7.53 \pm 7.25$ & $10.88 \pm 9.13$ & $14.98 \pm 20.00^{\mathrm{b}}$ \\
\hline \multicolumn{6}{|c|}{ Control group $(n=17)$} \\
\hline Baseline count & $28.53 \pm 9.22$ & $14.00 \pm 4.76$ & $13.06 \pm 7.44$ & $12.41 \pm 7.30$ & $17.94 \pm 8.59$ \\
\hline $7 \mathrm{~h}$ post-CAG & $26.53 \pm 15.05$ & $13.35 \pm 6.84$ & $11.53 \pm 9.75$ & $11.71 \pm 10.23$ & $16.82 \pm 14.11$ \\
\hline $24 \mathrm{~h}$ post-CAG & $28.94 \pm 14.49$ & $13.82 \pm 4.75$ & $14.53 \pm 10.45$ & $14.65 \pm 10.43$ & $20.06 \pm 13.86$ \\
\hline
\end{tabular}

Data are expressed as mean \pm standard deviation. ${ }^{\mathrm{a}} \mathrm{P}<0.05$ vs. baseline, ${ }^{\mathrm{b}} \mathrm{P}<0.01$ vs. baseline, ${ }^{\mathrm{c}} \mathrm{P}<0.05$ vs. the lowest value following baseline testing (at $7 \mathrm{~h}$ ) in the PCI group, ${ }^{\mathrm{d}} \mathrm{P}<0.01$ vs. the baseline count of the control group. $\mathrm{PCI}$, percutaneous coronary intervention; CAG, coronary artery angiography; $\mathrm{CD}$, cluster of differentiation; KDR, kinase domain receptor.
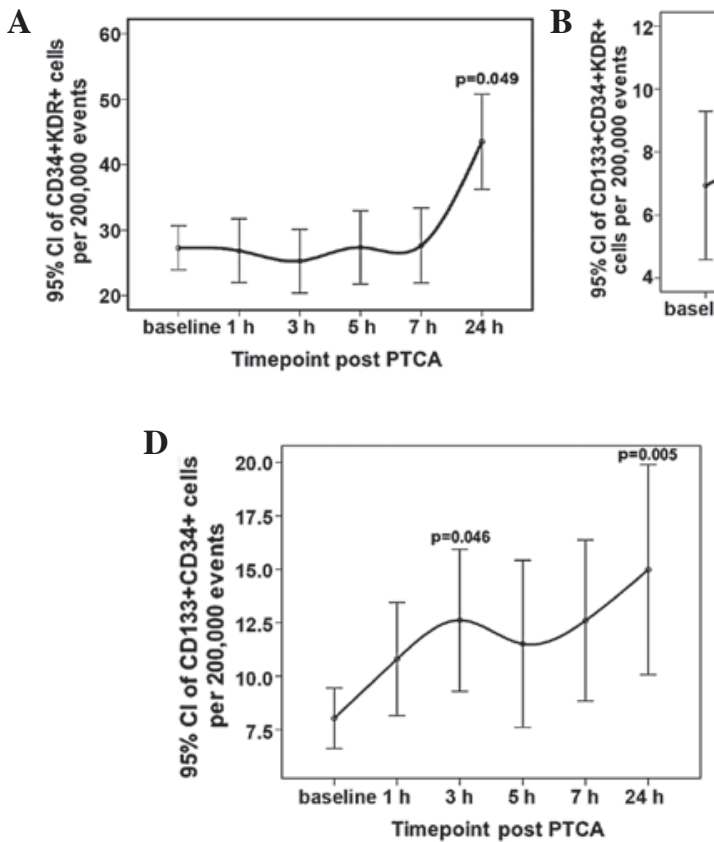
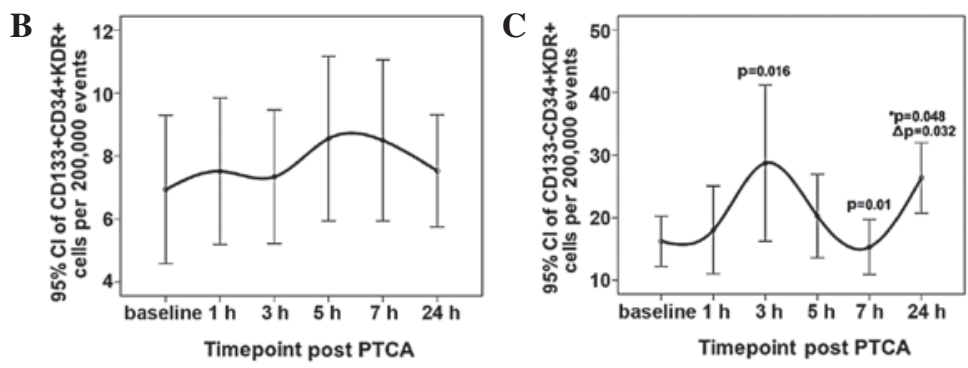

$\mathbf{E}$

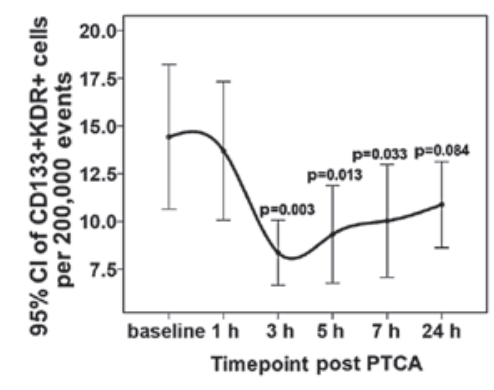

Figure 1. Error bar charts show (A) a stable CD34 $/ \mathrm{KDR}^{+}$subpopulation count during the early post-procedure stage (within $7 \mathrm{~h}$ ) and a small upregulation after $24 \mathrm{~h}$; (B) the $\mathrm{CD} 133^{+} / \mathrm{CD}_{3} 4^{+} / \mathrm{KDR}^{+}$subpopulation levels were stable during the procedure: The significantly low content in peripheral blood may be partly responsible for that but a dynamic equilibrium cannot be excluded; $(\mathrm{C})$ an early increase $(\mathrm{P}=0.016) 3 \mathrm{~h}$ post- $\mathrm{PCI}$ is observed, then a rapid decline $(\mathrm{P}=0.01) 6 \mathrm{~h}$ post-surgery is seen in $\mathrm{CD} 133{ }^{-} \mathrm{CD} 34^{+} \mathrm{KDR}^{+}$subpopulation with a delayed increase from both the lowest point at $7 \mathrm{~h}$ and the baseline value of this subpopulation of cells at $24 \mathrm{~h}$ post PCI $\left({ }^{\wedge} \mathrm{P}=0.032,{ }^{*} \mathrm{P}=0.048\right.$, respectively); (D) a gentle and significant increase is shown in $\mathrm{CD} 133^{+} / \mathrm{CD} 34^{+}$cells at 3 and $24 \mathrm{~h}$ following the balloon dilation; (E) a moderate reduction of the $\mathrm{CD} 133^{+} / \mathrm{KDR}^{+}$subpopulation was shown at $3 \mathrm{~h}$ post-procedure with the low status continuing until $24 \mathrm{~h}$ post PCI. CI, confidence interval; CD, cluster of differentiation; KDR, kinase domain receptor; PTCA, percutaneous transluminal coronary angioplasty.

to the baseline level was shown at $24 \mathrm{~h}$ post PCI $(\mathrm{P}=0.048)$. Small but significant increases were shown in $\mathrm{CD} 133^{+} / \mathrm{CD} 34^{+}$ cell counts at 3 and $24 \mathrm{~h}(\mathrm{P}=0.046$ and $\mathrm{P}=0.005$, respectively). The $\mathrm{CD} 133^{+} / \mathrm{KDR}^{+}$subpopulation showed a moderate reduction in count at $3 \mathrm{~h}$ after the procedure, remained reduced until $7 \mathrm{~h}$ post $\mathrm{PCI}(\mathrm{P}=0.003, \mathrm{P}=0.013$ and $\mathrm{P}=0.033$, at 3,5 and $7 \mathrm{~h}$ respectively), and then marginally increased at $24 \mathrm{~h}$, when the statistical significance of the difference relative to the baseline count was lost $(\mathrm{P}=0.084$; Table II).
Association between EPC phenotype and clinical factors. Partial correlation analysis was performed to investigate the association between the maximum change magnitudes of $\mathrm{CD} 4^{+} / \mathrm{KDR}^{+} \mathrm{EPCs}$ and clinical factors including age, gender, stent surface area and maximum stent inflation pressure. The results revealed that the maximum change magnitude of EPCs $\mathrm{CD} 4^{+} / \mathrm{KDR}^{+}$correlated negatively with basal C-reactive protein $(\mathrm{CRP} ; \mathrm{P}=0.034)$ and positively with body mass index (BMI), smoking and ACEI or angiotensin II receptor blocker 
Table III. Partial correlation analysis between the maximum change magnitudes of $\mathrm{CD}^{2} 4^{+} / \mathrm{KDR}^{+}$cells post-angioplasty and relative factors.

\begin{tabular}{lcr}
\hline Relative factors & Partial correlation coefficient & P-value \\
\hline Age & -0.2487 & 0.057 \\
BMI & 0.3007 & 0.021 \\
WBC & -0.1859 & 0.159 \\
Neutrophil ratio & 0.015 & 0.91 \\
Hs-CRP & -0.2759 & 0.034 \\
Surface of stent area & 0.2168 & 0.099 \\
Maximum dilation pressure of stent & -0.1541 & 0.24 \\
Stent surface area x maximum inflation pressure & 0.4467 & $<0.001$ \\
Gender & -0.2039 & 0.115 \\
Current smoking & 0.2969 & 0.02 \\
Current drinking & -0.1563 & 0.229 \\
Essential hypertension & -0.2208 & 0.087 \\
Diabetes & 0.1378 & 0.289 \\
ACEI or ARB treatment & 0.2845 & 0.026 \\
\hline
\end{tabular}

BMI, body mass index; WBC, white blood cell; Hs-CRP, high sensitivity C-reactive protein; ACEI, angiotensin-converting enzyme inhibitor; $\mathrm{ARB}$, angiotensin II receptor blocker; CD, cluster of differentiation; KDR, kinase domain receptor.

(ARB) drug treatment $(\mathrm{P}=0.021, \mathrm{P}=0.02$ and $\mathrm{P}=0.026$, respectively). There was also a positive correlation with the global injury integral (the product of the stent surface area and the maximum stent inflation pressure; $\mathrm{P}<0.001$; Table III).

\section{Discussion}

In the present study, the circulating CD133-, CD34- and KDR-marked progenitor cells were quantified and any changes in patients with exertional angina were examined at different time-points within $24 \mathrm{~h}$ pre- and post-angioplasty. On the basis of a previous study (1), the data of the present study demonstrated that mature EPCs (identified by CD133 $/ \mathrm{CD} 34^{+} / \mathrm{KDR}^{+}$ status) were more actively motivated to enter the peripheral blood or home to the local coronary endothelium when induced by PCI, as indicated by the earlier and more intensive up- and downregulation of the EPC count (2). The specific association between the motivation of $\mathrm{CD} 34^{+} / \mathrm{KDR}^{+} \mathrm{EPCs}$ and a number of clinical factors was probed during the early stages following PCI. Finally, the maximum changes of $\mathrm{CD} 34^{+} / \mathrm{KDR}^{+}$ EPCs were identified to correlate with BMI, CRP, current smoking habits and ACEI or ARB treatment $(0.01<\mathrm{P}<0.05)$, and particularly with the global injury integral from the PCI procedure $(\mathrm{P}<0.001)$. Allowing for possible sampling errors, it is ensured that global injury integral is the crucial contributor to $\mathrm{CD}_{34}+\mathrm{KDR}^{+} \mathrm{EPC}$ motivation.

A delayed increase of $\mathrm{CD} 34^{+} / \mathrm{KDR}^{+}$levels was observed $24 \mathrm{~h}$ post-PCI on the basis of the prior increase in CD133 $/ \mathrm{CD}^{2} 4^{+} / \mathrm{KDR}^{+} \mathrm{EPC}$ and the relatively constant level of $\mathrm{CD}_{133}{ }^{+} / \mathrm{CD} 34^{+} / \mathrm{KDR}^{+}$EPCs. Since CD133 is highly expressed in immature stem cells and lost during the differentiation to mature endothelial cells $(16,17)$, the $\mathrm{CD} 133^{+} / \mathrm{CD}^{2} 4^{+} / \mathrm{KDR}^{+}$ subpopulation is a precursor of $\mathrm{CD} 133-/ \mathrm{CD} 34^{+} / \mathrm{KDR}^{+}$cells. The undulating change of $\mathrm{CD} 133-/ \mathrm{CD}^{2} 4^{+} / \mathrm{KDR}^{+}$cell counts suggests that EPCs, particularly mature circulating EPCs, are preferentially recruited by homing signals such as stromal cell-derived factor-1 (SDF-1) (18), which is released from denudated endothelium. It is assumed that EPC subgroups with prior and robust mobilization may play a more important role in endothelial reparation.

Intracoronary stents are a potential vehicle for the delivery of novel therapies directly to the site of vascular injury. Gene-eluting stents that directly deliver naked plasmid DNA encoding for VEGF-2 may accelerate re-endothelialization and reduce lumen loss in animal models (19). If mature circulating EPCs (particularly CD133\%CD34 $/ \mathrm{KDR}^{+}$subpopulations) are preferentially recruited and home to sites of injury where balloons inflate or stents are deployed, we recommend promoting the 'capture' of $\mathrm{CD} 133^{+} / \mathrm{CD} 34^{+}$and $\mathrm{CD} 133^{+} / \mathrm{KDR}^{+}$ cells, or even the mature $\mathrm{CD} 133-/ \mathrm{KDR}^{+} / \mathrm{CD} 34^{+}$subpopulation of EPCs, by gene-eluting stent implantation to facilitate re-endothelialization. Secondly, it is suggested that a large-scale mobilization of EPCs from bone marrow may occur no later than $24 \mathrm{~h}$ after PCI, providing a valuable time-window for the application of measures to advance or intensify this process.

In the present study, an evaluation was carried out of whether any associations exist between the degree of damage and changes in EPCs induced by the combined effect of recruitment and homing. Damage to the endothelium originating from mechanical inflation was categorized into injury area and degree, which were mirrored by stent surface area and the maximum stent inflated pressure.

In the present study, various possible clinical factors were listed and individual correlations with the changes in $\mathrm{CD} 4^{+} / \mathrm{KDR}^{+}$EPCs were analyzed. It was confirmed that a positive correlation existed for $\mathrm{CD} 34^{+} / \mathrm{KDR}^{+} \mathrm{EPC}$ motivation with current smoking or ACEI or ARB administration, and a negative correlation with hs-CRP. This partially conforms with 
the results of certain published reports $(20,21)$. It is, therefore, reasonable to accept that, according to the present results, the mobilization of EPCs correlated negatively with hs-CRP and correlated positively with ACEI or ARB drug treatment. The present study found that positive correlations existed between the mobilization degree of EPCs and smoking or BMI. This shows that to a certain extent a more robust motivation can be stimulated post-PCI among respective populations. By contrast, cigarette smoking may stimulate the release of EPCs from bone marrow to repair the damaged endothelium and it may be an eligible reason underlying the mechanism of this positive connection.

The significant positive correlation between the global injury integral and EPC mobilization amplitude in the present study revealed that the degree of endothelial damage in the PCI procedure depends on both the contact area of the stent strut with the coronary endothelium and stent inflation pressure. A higher global injury integral usually represents a larger stent diameter, in particular with a higher inflation pressure. This may support complete lesion cover and good positioning during PCI in order to accelerate the endothelialization process. This also offers a new theoretical foundation for the post-inflation advocated by the angiography versus intravascular ultrasound-directed bare-metal coronary stent placement (AVID) trial (22). This suggests that more intensive and effective motivation of EPCs initiated post-dilation may contribute to the reparation of the damage to the endothelium caused by PCI, and then to a certain extent decrease the incidence of in-stent thrombosis or restenosis (23).

In the present study, blood samples were not collected at specified time-points, so no circadian rhythm was detected in the control group whereas a diurnal reduction of circulating EPCs has been recorded between 08.00 and 15.00 of $11-18 \%$ in healthy volunteers (24).

The present outcome does not completely agree with previous studies reported by Thomas et al (9) and Lee et al (10), in which a moderate but marked reduction of the $\mathrm{CD} 34^{+} / \mathrm{KDR}^{+}$ EPC phenotype was detected at 4 and $6 \mathrm{~h}$ post-PCI time-points compared with the baseline level. This difference is ascribed to respective enrolment criteria or pharmacological therapy; for example, diabetic patients were excluded by Thomas et al (9), yet Lee et al (10) targeted the dynamic mobilization of EPC in diabetics. In the present study some diabetic cases comorbid with hyperlipidemia or hypertension were enrolled. Furthermore, all patients were treated with statins. Diabetics of types I and II have been shown to have lower baseline EPC levels and dysfunctional progenitor cells in terms of proliferation, adhesion and angiogenic properties, resulting in delayed re-endothelization $(25,26)$. Statins can facilitate the mobilization of $\mathrm{CD}_{3} 4^{+}$and $\mathrm{KDR}^{+}$cells into the peripheral circulation (27) in a dose-dependent manner (28). Differences in the study population and interventional measures may confound the successive changes of circulating EPCs following PCI.

The present study had various limitations, including that the fact that the results indicated that single diagnostic angiography did not induce changes in the levels of EPCs (29). It may be inferred that the act of injecting contrast agent into the coronary artery is not a causative factor, although the possibility that the insertion of a sheath into the femoral artery causes arterial endothelial damage cannot be excluded and may possibly be a causative factor. Another limitation of this study is the fact that the number of patients was relatively small, which helps in understanding why no significant difference in EPC counts was found at baseline between the two groups. Furthermore, only the relative changes of EPC counts in peripheral blood were studied and no functional studies of the EPCs were conducted. All treated coronary arteries had TIMI grade 3 blood flow prior to the first balloon dilation and no iatrogenic myocardial infarction from PCI; hence, a disturbance due to inflammatory factors from necrotic myocardium can be excluded. Finally as there was no long-term follow up of these patients, a delayed and more significant mobilization of EPCs at $>24$ h post-PCI cannot be excluded.

In conclusion, endothelial injury from angioplasty can lead to time-dependent mobilization or homing of EPCs; mature EPC subpopulations are actively mobilized, and may contribute more to endothelial reparation; and the mobilization amplitude of the main EPC subpopulations is significantly influenced by the degree of endothelial injury and certain clinical factors.

\section{References}

1. Bakogiannis C, Tousoulis D, Androulakis E, et al: Circulating endothelial progenitor cells as biomarkers for prediction of cardiovascular outcomes. Curr Med Chem 19: 2597-2604, 2012.

2. Kwon O, Miller S, Li N, et al: Bone marrow-derived endothelial progenitor cells and endothelial cells may contribute to endothelial repair in the kidney immediately after ischemia-reperfusion. J Histochem Cytochem 58: 687-694, 2010.

3. Sen S, McDonald SP, Coates PT, et al: Endothelial progenitor cells: Novel biomarker and promising cell therapy for cardiovascular disease. Clin Sci (Lond) 120: 263-283, 2011.

4. Wojakowski W, Pyrlik A, Król M, et al: Circulating endothelial progenitor cells are inversely correlated with in-stent restenosis in patients with non-ST-segment elevation acute coronary syndromes treated with EPC-capture stents (JACK-EPC trial). Minerva Cardioangiol 61: 301-311, 2013.

5. Damman P, Klomp M, Beijk MA, et al; e-Healing Investigators: Twelve-month outcomes after coronary stenting with the Genous $^{\mathrm{TM}}$ bio-engineered R Stent ${ }^{\mathrm{TM}}$ in diabetic patients from the e-HEALING registry. J Interv Cardiol 24: 285-294, 2011.

6. Pelliccia F, Pasceri V, Rosano G, et al: Endothelial progenitor cells predict long-term prognosis in patients with stable angina treated with percutaneous coronary intervention: Five-year follow-up of the PROCREATION study. Circ J 77: 1728-1735, 2013.

7. Bonello L, Harhouri K, Baumstarck K, et al: Mobilization of $\mathrm{CD} 4^{+} \mathrm{KDR}^{+}$endothelial progenitor cells predicts target lesion revascularization. J Thromb Haemost 10: 1906-1913, 2012.

8. Shmelkov SV, St Clair R, Lyden D and Rafii S: AC133/CD133/Prominin-1. Int J Biochem Cell Biol 37: 715-719, 2005.

9. Thomas HE, Avery PJ, Ahmed JM, et al: Local vessel injury following percutaneous coronary intervention does not promote early mobilisation of endothelial progenitor cells in the absence of myocardial necrosis. Heart 95: 555-558, 2009.

10. Lee LC, Chen CS, Choong PF, et al: Time-dependent dynamic mobilization of circulating progenitor cells during percutaneous coronary intervention in diabetics. Int J Cardiol 142: 199-201, 2010.

11. Egan CG, Caporali F, Huqi AF, et al: Reduced levels of putative endothelial progenitor and $\mathrm{CXCR}^{+}$cells in coronary artery disease: Kinetics following percutaneous coronary intervention and association with clinical characteristics. Thromb Haemost 101: 1138-1146, 2009.

12. Garg R, Tellez A, Alviar C, et al: The effect of percutaneous coronary intervention on inflammatory response and endothelial progenitor cell recruitment. Catheter Cardiovasc Interv 72: 205-209, 2008

13. Banerjee S, Brilakis E, Zhang S, et al: Endothelial progenitor cell mobilization after percutaneous coronary intervention. Atherosclerosis 189: 70-75, 2006. 
14. Vasa M, Fichtlscherer S, Aicher A, et al: Number and migratory activity of circulating endothelial progenitor cells inversely correlated with risk factors for coronary artery disease. Circ Res 89: E1-E7, 2001.

15. Steiner S, Niessner A, Ziegler S, et al: Endurance training increases the number of endothelial progenitor cells in patients with cardiovascular risk and coronary artery disease. Atherosclerosis 181: 305-310, 2005.

16. Handgretinger R, Gordon PR, Leimig T, et al: Biology and plasticity of $\mathrm{CD}_{133^{+}}$hematopoietic stem cells. Ann NY Acad Sci 996: 141-151, 2003.

17. Foteinos G, Hu Y, Xiao Q, et al: Rapid endothelial turnover in atherosclerosis-prone areas coincides with stem cell repair in apolipoprotein E-deficient mice. Circulation 117: 1856-1863, 2008.

18. Yin Y, Zhao X, Fang Y, et al: SDF-1 alpha involved in mobilization and recruitment of endothelial progenitor cells after arterial injury in mice. Cardiovasc Pathol 19: 218-227, 2010.

19. Walter DH, Cejna M, Diaz-Sandoval L, et al: Local gene transfer of phVEGF-2 plasmid by gene-eluting stents: An alternative strategy for inhibition of restenosis. Circulation 110: 36-45, 2004.

20. Umemura T, Soga J, Hidaka T, et al: Aging and hypertension are independent risk factors for reduced number of circulating endothelial progenitor cells. Am J Hypertens 21: 1203-1209, 2008.

21. Kränkel N, Lüscher TF and Landmesser U: 'Endothelial progenitor cells' as a therapeutic strategy in cardiovascular disease. Curr Vasc Pharmacol 10: 107-124, 2012.
22. Russo RJ, Silva PD, Teirstein PS, et al; AVID Investigators: A randomized controlled trial of angiography versus intravascular ultrasound-directed bare-metal coronary stent placement (the AVID Trial). Circ Cardiovasc Interv 2: 113-123, 2009.

23. Fröbert O, Sarno G, James SK, et al: Effect of stent inflation pressure and post-dilatation on the outcome of coronary artery intervention. A report of more than 90,000 stent implantations. PLoS One 8: e56348, 2013.

24. Thomas HE, Redgrave R, Cunnington MS, et al: Circulating endothelial progenitor cells exhibit diurnal variation. Arterioscler Thromb Vasc Biol 28: E21-E22, 2008.

25. Tepper OM, Galiano RD, Capla JM, et al: Human endothelial progenitor cells from type II diabetics exhibit impaired proliferation, adhesion and incorporation into vascular structures. Circulation 106: 2781-2786, 2002.

26. Ii M, Takenaka H, Asai J, et al: Endothelial progenitor thrombospondin-1 mediates diabetes-induced delay in reendothelialization following arterial injury. Circ Res 98: 697-704, 2006.

27. Vasa M, Fichtlscherer S, Adler K, et al: Increase in circulating endothelial progenitor cells by statin therapy in patients with stable coronary artery disease. Circulation 103: 2885-2890, 2001.

28. Leone AM, Rutella S, Giannico MB, et al: Effect of intensive vs standard statin therapy on endothelial progenitor cells and left ventricular function in patients with acute myocardial infarction: Statins for regeneration after acute myocardial infarction and PCI (STRAP) trial. Int J Cardiol 130: 457-462, 2008.

29. Mills NL, Tura O, Padfield GJ, et al: Dissociation of phenotypic and functional endothelial progenitor cells in patients undergoing percutaneous coronary intervention. Heart 95: 2003-2008, 2009. 